\title{
@®९) Eric Weil e o papel da educação humanística no contexto da cultura técnico-científica
}

\author{
Judikael Castelo Branco*
}

\begin{abstract}
Resumo: O artigo explicita os termos essenciais da resposta de Eric Weil à pergunta sobre o papel da educação humanística num contexto de hegemonia da cultura técnico-científica. Para tanto, a estrutura do texto parte da questão da educação no espaço de tensão entre o desenvolvimento da ciência de um lado, e da moral, de outro. Num segundo nível reflexivo, esta tensão se dá, concretamente, na relação entre educação e instrução. Finalmente, impõe-se perguntar pelo papel da educação para a compreensão do nosso tempo, tempo reconhecidamente modelado pelas ciências.
\end{abstract}

Palavras-chave: Eric Weil. Educação. Instrução. Humanidades.

\section{Eric Weil, humanistic education and the cultural hegemony of technology}

\begin{abstract}
This article is purported to clarify the essential terms that Eric Weil used to answer the questions related to the role of the humanistic education in a social milieu predominantly shaped by science and technology. It will initially address the tension between the development of science and the development of morality. In addition to this, it will examine the tensions between education and formal instruction. In the end, this work will search for the understanding of the contribution that education can bring about to societies modeled by empirical sciences.
\end{abstract}

Keywords: Eric Weil. Education. Instruction. Humanities.

\footnotetext{
* Doutor em Filosofia pela Universidade Federal do Ceará (UFC). Professor da Universidade Estadual do Ceará (UECE). E-mail: judikael79@ hotmail.com
} 


\section{Eric Weil et le rôle de l'éducation humaniste dans le contexte de la culture technico-scientifique}

Resumé: L'article explicite les termes essentiels de la réponse d'Eric Weil à la question sur le rôle de l'éducation humaniste dans un contexte de l'hégémonie de la culture technico-scientifique. Le texte part de la question de l'éducation dans l'espace de la tension entre le développement de la science et le développement de la morale. Dans un second niveau de réflexion, cette tension se produit dans la relation entre l'éducation et l'instruction. Enfin, il doit demander sur le rôle de l'éducation pour la compréhension de notre temps, reconnue comme le temps modélisée par les sciences de la nature.

Mots-clé: Eric Weil. Éducation. Instruction. Humainités.

\section{Introdução}

Este artigo explicita os termos essenciais da resposta de Eric Weil à questão sobre o papel da educação humanística no contexto de hegemonia da cultura técnico-científica. A relevância do tema se põe como preocupação pelo capital cultural humanístico como parte da identidade da tradição ocidental e se impõe a partir das ações políticas e sociais que manifestam um interesse quase exclusivo pelas organizações educacionais promotoras das áreas do conhecimento que contemplam as necessidades técnicas da sociedade. Por sua vez, o interesse pela obra de Weil se justifica não apenas pela sua descrição das complexas condições da relação entre educação e instrução na sociedade moderna, mas, sobretudo, porquanto o autor compreende a importância das humanidades numa civilização que se assenta, fundamentalmente, no conhecimento científico.

Eric Weil publicou, em 1946, "L'idée d'education dans l'insegnement américan", e desde então as humanidades se tornaram objeto constante da sua reflexão. No que concerne ao tema, subjaz, como 
em toda a sua obra, a acepção clássica da filosofia como sabedoria para a educação ${ }^{1}$, o que leva a tomá-la como a disciplina humanística por excelência. Deste modo, o interesse de Weil pelas humanidades se integra ao conjunto da sua reflexão sobre a identidade e a tarefa da filosofia ${ }^{2}$, especialmente nas condições do mundo moderno, a partir da consideração da sua história e do seu desencantamento.

O interesse pela cultura humanística é parte das bases nas quais o sistema weiliano se ergue. Porém, se por um lado esse interesse subjaz à sua reflexão sistemática, por outro, é somente no conjunto completo da sua obra que o papel das ciências humanas encontra um sentido. ${ }^{3}$ A relação entre os textos sobre a educação e as demais partes da obra de Eric Weil está nas referências que os primeiros fazem a temas desenvolvidos na Filosofia política.

Para alcançar seu objetivo, o texto parte do status quaestionis da educação no espaço de tensão entre o progresso científico e o desenvolvimento moral. Em um segundo momento, essa mesma tensão é retomada na relação entre a educação e a instrução. Finalmente, impõe-se perguntar pelo papel da educação e do homem educado para a compreensão de um tempo modelado pelas ciências.

\footnotetext{
1 Antecipando algumas conclusões, concordamos com as palavras de Roberto Saldías (2014, p. 99) quando afirma que "Eric Weil entende a educação como uma ação moral, social e política que busca estabelecer na história uma humanidade razoável, sem violência. A educação constitui assim uma sorte de círculo dialético que parte do homem, em sua condição de ser finito e razoável, e que retorna constantemente a ele com o objetivo de julgar e libertá-lo de tudo aquilo que se instala de maneira negativa e violenta".

${ }^{2}$ Sobre a metafilosofia em Weil, ver Strummiello (2006, p. 101-119).

${ }^{3}$ A obra de Weil, segundo a interpretação de Gilbert Kirscher (1989, p. 5-9), se apresenta numa estrutura concêntrica em três diferentes níveis. Num círculo mais periférico, estão suas recensões e críticas, publicadas, sobretudo, nas revistas Recherches Philosophiques e Critique. No segundo círculo, sua reflexão se volta diretamente para os vários discursos filosóficos que se sucederam na história, entre os quais dedica particular interesse às questões presentes em Aristóteles, Kant e Hegel. No círculo mais interno encontra-se a sua magnum opus: a Lógica da filosofia (1950), a Filosofia política (1956) e a Filosofia moral (1961). Nestas, o autor assume propriamente a questão fundamental da filosofia em sua universalidade e em suas determinações morais e políticas. Além do texto de Kirscher, uma apresentação sistemática da filosofia de Eric Weil se encontra em Perine (1987) e Kluback (1987).
} 


\section{A educação entre a fé na ciência e o problema do desenvolvimento moral}

Para Eric Weil, o ponto essencial da educação, enquanto "problema do nosso tempo", é assumi-la como parte da questão do sentido nas condições próprias da sociedade moderna. Em outras palavras, exige-se a consideração da pergunta pelo sentido em meio às condições do homem livre na sociedade produzida pela ciência e pela técnica, problemática que deve ser explorada nos diferentes ângulos impostos pelas mudanças do quadro referencial social. Logo, a preocupação de Weil ao retomar o tema é o esforço para ilustrar, em diferentes perspectivas, o essencial da educação e suas implicações sociais. Esse esforço assume a forma da reflexão sobre as contradições sociais no quadro da hegemonia da cultura científica e da crescente suspeita acerca do papel da cultura humanística. Ainda que a reflexão weiliana se volte mais à definição do problema da educação do que ao seu conteúdo, ela abre espaço à pergunta sobre a mediação necessária entre a capacitação do homem para pensar, de um lado, e para orientar sua ação dentro da sua condição social efetiva, de outro.

Pensando o contexto social moderno, o ponto de partida da reflexão de Weil, elemento compartilhado com outros pensadores, é justamente a relação entre a instrução e a educação, ou seja, entre a cultura científica e aquela humanística. ${ }^{4}$ Porém, é especificamente weiliano ver nessa relação a analogia perfeita para pensar aquela entre o progresso técnico e as condições morais, sempre à luz do risco do "espírito pseudocientífico [que] ameaça o nosso tempo" (WEIL, 1993, p. 140). Risco que se apresenta ainda como aquele potencialmente mais grave "de uma humanidade livre da necessidade e da opressão exterior, mas não preparada para dar um conteúdo à sua liberdade"; neste novo contexto, "não seria exagerado afirmar que não existe problema mais

\footnotetext{
${ }^{4}$ Como é também o caso, por exemplo, de Hannah Arendt, quando, em 1954, escreve o texto "Crisi in Education". (ARENDT, 1983, p. 173-196).
} 
importante nem mais urgente que aquele da educação" (WEIL, 2003a, p. 309).

Eric Weil, ao assumir um interesse propriamente filosófico, se orienta na direção de um horizonte mais amplo do que o da maioria dos pedagogos e dos especialistas em educação, pois, concretamente, quando "o único problema é aquele da educação do cidadão" (WEIL, 1993, p. 134), a reflexão deve se voltar para o debate acerca do papel da cultura humanística e da instrução técnica na realização do homem. Para tanto, é essencial compreender dois fatores fundamentais no nosso atual contexto civilizacional: a fé na ciência e a pergunta sobre as condições de possibilidade do desenvolvimento moral do indivíduo.

Concernente à fé na ciência, esta conhece, historicamente, dois momentos essenciais. Primeiro, o processo, presente já no início do Iluminismo, do abandono da confiança na providência, e, depois, a perda definitiva da "inocência" da ciência no século passado. Quanto ao segundo momento, com efeito, os instrumentos e os meios fornecidos pela ciência e testemunhados, sobretudo, a partir da Segunda Guerra, se mostraram incompreensíveis nos limites das antigas categorias dos discursos éticos sobre a violência. ${ }^{5}$ Trata-se da questão das novas formas de violência, possibilitadas pela opulência sem meta do Ocidente desenvolvido e diante da qual tanto a educação como a filosofia devem ser pensadas. Dito de outro modo, qual o seu lugar num contexto social caracterizado por um incrível excedente de meios e por uma imensa carência de fins.

Quanto à preocupação acerca da moral, Eric Weil não apenas retoma o significado da educação partindo da compreensão do papel da cultura humanística no contexto em que aquela técnico-científica é hegemônica, mas também da percepção da crítica ao estilo de vida

\footnotetext{
${ }^{5}$ O problema da completa desproporção entre os meios disponíveis, de um lado, e os fins que no passado justificaram o uso da violência, de outro, preocupou praticamente todos os grandes filósofos do século passado. Numa perspectiva que cientemente se restringe ao campo do pensamento político, (ARENDT, 1972, p. 103-184). Para uma aproximação panorâmica do tema da violência na filosofia contemporânea (STRUMMIELLO, 2001).
} 
proposto pela sociedade moderna. A reflexão weiliana vai, então, na direção de uma concreta proposta de regeneração moral e política fundada sobre a clareza tanto da natureza dos problemas quanto da precisão dos seus termos. É, por isso, na reflexão moral que o problema da educação ganha sua devida dimensão. Em suma, é sempre o caso de pensar a questão da liberdade do homem e das condições desta mesma liberdade. ${ }^{6}$

O lugar da educação na obra weiliana é uma mostra da particularidade da sua perspectiva. Embora extrapole os interesses desta pesquisa, vale lembrar, por exemplo, que Weil lida com o tema ao lançar as bases morais da reflexão política, quer dizer, quando pensa a fundamentação moral da política, o que, mais uma vez, o põe em aberta dissonância com o contexto filosófico da segunda metade do século passado. $^{7}$ De fato, no plano histórico-político, a análise deve se voltar à sociedade moderna, na qual a questão da educação assume a sua especificidade. Levando em conta os fundamentos da própria autocompreensão da sociedade, trata-se de situar a educação no espaço

\footnotetext{
${ }^{6}$ Como afirma o intérprete português, Luis Bernardo (2011, p. 23-24), “Weil estabelece (...) a relação intrínseca entre liberdade e educação: se a liberdade depende da educação, a verdadeira educação é educação para a liberdade, na vontade livre do indivíduo que aceita o que lhe é socialmente proposto, ao reconhecer a razão existente na moral concreta e ao pretender, por esse motivo, agir segundo as suas regras. Esta relação circular, por um lado, determina uma antinomia entre doutrinação e educação, ao invés do que supõe a maioria das perspectivas moralistas que tendem para insistir na necessária imposição da parénese convencional e/ou da axiologia imputada à tradição, quanto, por outro, define uma impossibilidade prática, a de que esse condicionamento venha a produzir um caráter efetivamente moral".

${ }^{7}$ Neste ponto também, a perspectiva weiliana se alinha à de Kant, pondo na reflexão moral o fundamento da questão acerca do sentido da política. Na Filosofia política, a educação é desenvolvida no capítulo dedicado à moral, o que faz com que assuma, na obra como um todo, um papel não indiferente. Isto nos leva a discordar de Michel Soetard quando afirma que "não se pode dizer que a educação tenha um papel primordial na obra de Eric Weil" (SOETARD, 1984, p. 289). O professor Soetard argumenta a partir da ausência do tema na Lógica da filosofia e do pequeno aceno que encontra na Filosofia moral; mas, numa leitura sistemática, resta saber qual seria o lugar para o seu desenvolvimento na primeira e qual a necessidade de tratar novamente do assunto na segunda. Este aspecto, a nosso ver essencial à compreensão dos termos da questão, foi negligenciado na tese defendida por Aparecido de Assis (2016) acerca da educação em Weil.
} 
de tensão criado entre as condições subjacentes à organização da sociedade industrial de massa e as exigências das suas relações com o corpo político. Logo, não pode visar exclusivamente à inserção exitosa dos indivíduos no mecanismo social pela qualificação para o trabalho, impõe-se, também, a difícil tarefa da sua transformação em sujeitos aptos à participação da discussão para a solução dos problemas que interessam a todos. ${ }^{8}$

A relação entre a educação e a participação positiva na condução dos assuntos coletivos não aparece na obra weiliana de maneira fortuita, mas em acordo com a sua interpretação de Aristóteles. Com efeito, em "L'antropologie d'Aristote", Weil sublinha a felicidade como o objetivo da vida humana - ou o contentamento - bem como o fato de que só o homem educado pode reconhecer a própria felicidade (WEIL, 1991, p. 9-43). Logo, a educação é uma questão que toca eminentemente o terreno político, porquanto a sua falta compromete os fins últimos da organização da comunidade. Os referidos fins são fundamentais justamente porque se põem como alicerce e horizonte da vida social atual, a saber, o reconhecimento da democracia como

\footnotetext{
${ }^{8}$ Trata-se, concretamente, da inserção num corpo político democrático assentado em alguns dos princípios fundamentais da modernidade. Weil toma a democracia como tema específico em dois textos do mesmo período, a saber, no início da década de 1950 . No primeiro caso, trata-se da sua resposta a um pedido da UNESCO, "Democracy in a world of tensions" (WEIL, 1951, p. 425-442), no segundo, de um escrito pouco comentado, inclusive por aqueles que se dedicam à obra weiliana, "Limites de la démocratie" (cf. WEIL, 1950, p. 35-39). A questão, tomada em seus termos próprios, apresenta, ao mesmo tempo, a dimensão do que cabe à educação e à tarefa do filósofo-educador, reencontrando, assim, a verdadeira natureza da sua função social. Como assevera Marcelo Perine: "a discussão aberta e regrada pela lei, em vista das decisões políticas e a democracia, que é a forma mais elevada da vida em comum dos homens e que se define 'pela discussão racional e razoável'. Eis que o filósofo reencontra, assim, seu lugar, seu papel, sua tarefa que precocemente debutou com Sócrates na prematura democracia grega. O filósofo-educador não tem conselhos a dar aos políticos por profissão. Ele permanece homo theoreticus e não age à maneira do homo politicus. Sua ação, real no mais alto grau, se exerce no plano da consciência, e é ação enquanto tomada de consciência, universalmente válida e, portanto, ação sobre todos, inclusive o homem político, mas não ação imediata sobre as instituições e as decisões da comunidade, da sociedade e do Estado" (PERINE, 2004, p. 68). Acerca da relação entre o homem político e o homem teórico, ver M. Soares (1998).
} 
modelo ideal de governo e a consecução das condições materiais requeridas à sempre desejada vita bona (WEIL, 1993, p. 138). Em outros termos, se, para o homem moderno, a finalidade da sociedade é a vita bona e o meio de alcançá-la, a criação das condições materiais, o empenho fundamental da sociedade industrial de massa será a difusão dos conhecimentos científicos e das habilidades técnicas para a participação dos seus processos produtivos e dos seus benefícios. ${ }^{9}$ Trata-se, então, de inculcar no indivíduo a aceitação do princípio da eficácia, "sagrado" para a sociedade moderna, como valor pessoal. ${ }^{10}$

$\mathrm{O}$ ideal moderno de vita bona exige, portanto, um alto grau de instrução, tanto quanto pede ao "filósofo-educador" (WEIL, 1996a, p. 9) uma reapresentação da natureza e da tarefa da educação humanística. ${ }^{11}$ Parte da originalidade da posição weiliana é considerar a proposta de uma relação alternativa entre educação e instrução como um falso dilema. ${ }^{12}$

\footnotetext{
${ }^{9}$ Nos contornos assumidos pela sociedade moderna, "educação e política, inseparáveis uma da outra, só podem tender para um único fim: instituir o regime de mercado, deixar que as diferenças se confrontem, entre os indivíduos e entre as comunidades. Todos os indivíduos devem participar da técnica para ter chances iguais, todas as nações devem entrar em competição no mercado a fim de contribuir para o progresso. Uma sociedade civilizada proporcionará aos seus membros, portanto, uma instrução científica que desenvolva suas faculdades de trabalho (...)" (WEIL, 1996a, p. 219-220).

${ }^{10}$ A noção de sagrado é particularmente importante na filosofia de Eric Weil. No que concerne ao tema que nos interessa aqui, esta afirmação não se justifica apenas pela constância com que o termo aparece, mas, sobretudo, pelo seu papel na compreensão da sociedade moderna. Dando a palavra a Weil (1996b, p. 65), o sagrado "é o conceito (que não existe necessariamente como conceito formal na sua consciência, mas, por exemplo, sob a forma de tradição, regra de conduta, mito) (...) que fornece [à comunidade] o meio de distinguir entre o essencial e o inessencial, entre o bem e o mal, e que, consequentemente, não pode ser depreciado por nenhum argumento, porque todo argumento contrário se situa, por ser contrário, do lado do mal". Sobre o sagrado em Weil, ver D. Lins Júnior (2016, p. 249-262).

11 “A tarefa educativa do filósofo consiste (...) em colocar sem descanso a pergunta pela educação em meio das comunidades históricas e dos Estados particulares e, ao mesmo tempo, interrogar as condições e as determinações que a sociedade moderna - sociedade de controle progressivo da natureza - impõe à ideia mesma de educação e às suas instituições" (SALDÍAS, 2014, p. 100).

${ }^{12}$ A posição weiliana é, portanto, de raro equilíbrio ao evitar, seja a idealização dos resultados da ciência, seja a busca do retorno a um passado idílico de uma felicidade
} 


\section{Humanidades ou ciências? O falso dilema entre educação e instrução}

O problema da relação entre instrução e educação se pôs definitivamente no século XIX, com a ideia de "educação popular", cujo ideal se traduz na difusão de competências básicas como ler, escrever e contar. Não se trata de um projeto secundário, mas da via capaz de assegurar a dinâmica própria do progresso técnico, científico e social que repensa continuamente seus métodos e técnicas em vista da eficácia do trabalho social. Desta feita, a instrução se dá como "formação de um indivíduo útil à coletividade" (CANIVEZ, 1985, p. 532). Neste cenário, a noção de sagrado da sociedade moderna e o fim da instrução na formação de trabalhadores úteis, põem as bases para a autocompreensão do indivíduo como "força produtiva sob a pressão das circunstâncias” (WEIL, 1996b, p. 77); não restando entre os indivíduos outra regra além da competição, na qual o valor de cada um é medido tanto pela eficiência na própria função quanto pela dificuldade de substitui-lo na organização racional do trabalho. ${ }^{13}$

originária. $\mathrm{O}$ argumento definitivo, porém, pode ser tomado da própria experiência, pois, concretamente, "entre os opositores do progresso, poucos se deixam arrastar pelo desprezo do progresso na forma de rejeição das suas contribuições para as comodidades da vida. Certamente, a eletricidade, a água corrente, a possibilidade de viajar ou de visitar os museus, de andar pelas ruas sem o perigo de receber na cabeça o conteúdo de toda sorte de recipientes domésticos, a certeza de encontrar em determinados endereços o que se necessita ou tudo o que se deseja" (WEIL, 2003, p. 300).

13 "A instrução deve dar ao indivíduo suas chances na competição social, isto significa também que ele deve se esforçar para desenvolver entre as suas possibilidades aquelas que são, na situação presente, mais úteis e rentáveis para a coletividade. Ao mesmo tempo, este imperativo cria as condições de uma "competição escolar" cujo princípio, que é o princípio da competição social em geral, será aquele em que os indivíduos não reconhecem obstáculos além de seus próprios limites, isto é, os limites de suas capacidades e de sua vontade de colocá-las em prática" (CANIVEZ, 1985, p. 533). Evidentemente, numa sociedade em que a economia se tornou o fim da própria organização social, este valor pessoal se traduz no acesso do indivíduo a períodos de tempo livre e, sobretudo, a bens de consumo sempre mais sofisticados. 
O quadro fica completo ao retomar aquilo que já dissemos sobre a fé na ciência. De fato, "a ciência (...) fez da nossa civilização o que ela é” (WEIL, 1991, p. 268), e longe de tornar a educação obsoleta, isto a torna uma questão inescapável, imprescindível, pois também neste cenário, e talvez como em nenhum outro, "é preciso ser capaz de pensar retamente" para tirar, diante dos casos concretos da vida, as conclusões razoáveis apropriadas; "é preciso ser capaz de se exprimir, [pois] não há democracia sem comunicação"; "é preciso saber julgar com pertinência", porque a complexidade da vida real esvazia toda forma de neutralidade intelectual, e, finalmente, "é preciso saber escolher entre os valores, discernir aqueles autênticos e neles se engajar" (WEIL, 1993, p. 135-136). O homem educado aparece finalmente descrito como aquele capaz de pensar, de se exprimir, de deliberar e de se comprometer; isso mostra que a educação tem como tarefa primordial "levar o indivíduo a colocar a questão moral" (CANIVEZ, 1985, p. 551).

Em vista da superação do aparente dilema, volta-se mais uma vez à necessidade de formar homens que sejam, ao mesmo tempo, dotados de competência científica e de eficiência técnica e capazes de responder às exigências para a construção da democracia. A dificuldade surge quando a sociedade moderna vê o indivíduo exclusivamente a partir de sua utilidade no mecanismo social, e o mantém "essencialmente insatisfeito" (WEIL, 1996b, p. 93). Neste quadro, não apenas “o intelectual não [é] um cidadão melhor que o técnico" (WEIL, 1993, p. 135), mas pode ser tomado inclusive como o indivíduo dispensável. Do mesmo modo, extrapolar a consideração da importância da técnica e permitir que a instrução suplante a educação conduz, invariavelmente, ao esvaziamento de um princípio fundamental da sociedade moderna, afinal, "sem [educação], falar de democracia (...) é simplesmente uma brincadeira” (WEIL, 1993, p. 135). Evidentemente, a distinção e a complementariedade entre instrução e educação devem ser entendidas a partir do papel da primeira na sociedade moderna. De fato, numa 
sociedade em que se busca "riqueza, segurança e conforto" (WEIL, 2003a, p. 313), o primado problemático é dado à instrução. ${ }^{14}$ Concretamente, porém, se a distinção está de antemão bem estabelecida, a falta de uma perspectiva de complementariedade se apresenta amplamente atestada em alguns fenômenos sociais facilmente observados. Em primeiro lugar, a instrução parece autossuficiente em muitos institutos profissionalizantes e centros de pesquisa de alta especialização técnica. Em segundo lugar, a crescente preocupação com a instrução nos programas escolares parece confirmar o trabalho técnico como único destino possível na nossa sociedade.

Weil permanece fiel à convicção de que, para sair do perigo de uma formação técnica ou humanística esvaziadas, é preciso iniciar o quanto antes "a transmissão da herança comum que nos veio de Jerusalém e de Atenas - enriquecida pela sistematização do pensamento (obra da escolástica) - pelas descobertas e invenções que começam na Renascença, enfim, pela técnica moderna” (WEIL, 1993, p. 137). A questão diz respeito à realização do humano no homem enquanto ser agente e pensante. ${ }^{15}$ Se a sociedade moderna exige dos

\footnotetext{
${ }^{14}$ Esse primado é alicerçado justamente pelo tipo de ciência que justifica e promove o desenvolvimento da técnica que por sua vez orienta a instrução. Se o alicerce está na ciência natural, o fenômeno socialmente mais evidente é aquele da especialização essencial à organização racional do trabalho: "A ciência se complica continuamente, e a especialização, consequência da repartição das tarefas, faz com que a mente mais poderosa já não consiga enxergar a ciência em sua totalidade. Ela se constitui em uma multidão de ciências, todas relacionadas à ciência una, mas a ela relacionadas apenas para o filósofo, não para o especialista; a natureza, a totalidade do mensurável, é recortada em áreas, e o homem que se dedica a apenas uma delas esquece facilmente a existência das outras. Isso é particularmente verdadeiro quando se trata de procedimentos socialmente úteis; pois visto que essa utilidade é parcial, ela coloca em perigo, justamente por seu sucesso, o progresso da ciência que, ocupada em explorar os conhecimentos adquiridos, negligencia o desdobramento de novos terrenos. Ora, esse é o objetivo essencial da ciência, e uma sociedade que o perde de vista deixa de ser comunidade do progresso para voltar a ser comunidade do trabalho tradicional" (WEIL, 1996a, p. 222).

${ }^{15}$ O problema apenas se impôs: "se o perigo não é tão iminente, ele, todavia, começa a se desenhar: estamos apenas no início da era das máquinas, sentimos somente os primeiros efeitos da medicina moderna: e já atualmente a duração média da vida aumenta continuamente, e a parte consagrada ao trabalho diminui; como conservar a saúde moral da
} 
indivíduos um grau mínimo de domínio técnico para a participação no trabalho organizado, a instrução, mesmo sem ser a educação em sentido pleno, figura como educação à racionalidade do trabalho. É desta maneira que se reconhece o caráter essencialmente educativo "desse grande educador que, na linguagem corrente, chama-se a necessidade" (WEIL, 1996b, p. 201), através da qual o anônimo mecanismo social age sobre indivíduos instruídos (NGUYEN-DINH, 1996, p. 83).

Para o nosso quadro referencial social, aquele de uma sociedade "mundial", "calculista, materialista e mecanicista" (WEIL, 1996b, p. 68-71), a instrução é, justamente, a condição da inserção do indivíduo no seu mecanismo. A questão aqui é compreender que esta mesma inserção não é o caso da mera instrumentalização ou da simples redução do indivíduo à sua função social; trata-se, antes, de uma condição ao mesmo tempo necessária e insuficiente à educação. Em outros termos, se não existe educação fora do contexto social, no presente, não há participação neste contexto sem um razoável grau de instrução. Nas palavras de Patrice Canivez (1985, p. 536), “a inserção do indivíduo na atividade coletiva é a inserção num sistema de regras codificadas pela lei positiva, e por isso já é educação à não violência, à razão"16, o que permite descrever a relação entre instrução e educação como verdadeira "circularidade" (CANIVEZ, 1985, p. 539).

sociedade sem uma educação que prolongue os seus efeitos durante toda a existência e lhe dê conteúdo, valor e dignidade? (...) pode-se abandonar adolescentes e adultos ao ‘passatempo' e à inação?’ (WEIL, 1993, p. 137).

${ }^{16} \mathrm{Na}$ Lógica da filosofia, na categoria da Condição - aquela que lança as bases da compreensão do discurso por trás da atitude do homem na sociedade moderna -, fica patente o fato de que junto com a instrução vem uma série de normas (não escritas) que regram a conduta do indivíduo no mundo laboral. Numa sociedade que se funda em prol da organização racional do trabalho, estas mesmas regras assumem um papel fundamental na compreensão do indivíduo sobre a sua ação e, consequentemente, na sua autocompreensão: "honestidade nas relações econômicas, defesa da comunidade da qual [o indivíduo] faz parte e que lhe dá a possibilidade de viver de modo civilizado, ardor no trabalho, seja ele qual for, esforço em prol do maior bem-estar possível - eis tudo o que lhe diz respeito, porque é tudo o que diz respeito à sociedade" (WEIL, 1996a, p. 224-225). 
O problema se apresenta na forma de três diferentes questões. Primeiro, trata-se da pergunta sobre como fazer com que o homo laborans se decida, livremente, pela educação e não só pela instrução. Segundo, como dar a esta decisão a extensão da educação de massa. Finalmente, como apresentar a educação como uma necessidade para o homem moderno. A resposta de Weil assinala a necessidade da educação não em vista demandas sociais, mas justamente pelos resultados alcançados pela organização racional do trabalho, pois

A perfeita organização racional seria a vitória total do homem sobre a natureza externa; seria a libertação total do homem com relação à natureza, mas, criaria, ao mesmo tempo, um vazio no homem que teria à sua disposição a totalidade do seu tempo. Porém, reduzido a puro ser social, ele não usaria sensatamente esse tempo. A menos que o homem não renuncie a todo sentimento, o que teríamos depois da transformação total da natureza exterior seria o reino do tédio, único sentimento sobrevivente, um tédio que não estaria mais insatisfeito com isto ou aquilo, com tal imperfeição, tal necessidade, tal injustiça social, mas com a própria existência, o que levaria rapidamente à destruição violenta do estado ideal alcançado. Pode-se pensar sem contradição que o homem liberte-se de todo sentimento, mesmo do tédio, e a humanidade transforme-se num formigueiro (WEIL, 1996b, p. 94).

Não surpreende, portanto, encontrar na nossa sociedade de indivíduos ao mesmo tempo "civilizados" e completamente entediados; donde decorre sublinhar que se "a instrução e o progresso material são as condições indispensáveis [à consecução da liberdade]”, "quando são considerados como fins, é bem possível que não se destruam mutuamente, mas sejam destruídos pelo tédio e pelo desespero dos homens" (WEIL, 2003a, p. 308-309). ${ }^{17}$ É o que Eric Weil aponta ao

\footnotetext{
17 A nosso ver, na obra de Eric Weil, o tédio é mais do que o sentimento geral de inquietação resultante das condições que caracterizam a sociedade moderna. De fato, quando Weil se volta à condição do indivíduo dentro do mecanismo social, o tédio figura como o elemento da passagem do momento descritivo àquele propriamente problemático da análise. Mais uma vez, a opção de Weil é permanecer numa perspectiva propriamente filosófica. É justamente esta perspectiva que se evidencia na análise que Patrice Canivez
} 
tematizar o tédio que envolve toda a nossa civilização, o que aparece, quer em "Education as a problem for our time", quer em "La science et la civilisation moderne ou Le sens de l'insensé", texto de 1965. De fato, as ciências da natureza se reduzem diante do sagrado da sociedade a instrumentos do progresso material, desprovidas de um real valor a propor ao homem. Este, insiste o autor, encontra seus valores apenas no mundo "que se manifesta na história" e que é descrito nas humanidades. Em outras palavras, além do bem-estar e do tempo livre,

faz do tema, o tédio não é diretamente ligado ao sentimento apenas, mas mais profundamente à linguagem e ao discurso, isto é, como "uma linguagem que não permite pôr nem pensar o problema da ação de um sujeito livre, porque esta linguagem, essencialmente objetivante, não dá espaço para o conceito de sujeito, quer dizer, para o conceito de um ser que, deixando um momento de ser para um outro, se percebe e se quer [ser] para si. Esta linguagem postula, portanto, uma liberdade que não pode perceber e que, quando define seus próprios fins, estes lhe aparecem como gostos, humores, fantasias, pulsões, enfim, como irracionais, embora, em princípio, uma ciência deveria poder demonstrar seu mecanismo" (CANIVEZ, 1985, p. 543). Sobre o efeitos do tédio na sociedade moderna, podemos ver dois trechos de Weil que, a nosso ver, não deixam dúvida sobre a importância do tema para o filósofo: "Em todos os países avançados do nosso mundo podemos observar, e justamente nas camadas sociais mais providas dos bens que produz o trabalho social, o terrível fenômeno que estamos sempre tentados a tomar com ânimo leve e sorridente, quero dizer, o tédio, o vazio da existência, a falta de um significado da vida - e deduz-se daí a criminalidade absurda, não a boa e velha criminalidade compreensível, explicável pela necessidade, o desejo insatisfeito, a inveja, o ciúme, a revolta individual; não: trata-se de uma criminalidade que não se explica, ou melhor, que se pode explicar e que explicam os próprios criminosos pelo tédio, pela necessidade obsessiva de outra coisa, de um novo estímulo, de uma sensação que ainda não tenha perdido completamente o gosto e o interesse" (WEIL, 2003a, p. 131). Numa passagem da Filosofia política coloca com outras palavras os efeitos das mesmas causas: "A prova é dada pelo número de desequilibrados (dos que qualificam a si mesmos deste modo) nas sociedades mais avançadas: suicidas, neuróticos, adeptos de falsas religiões, (que são apenas fugas diante da compreensão e não modos de compreender a realidade, filosoficamente insuficientes, mas válidos em si), alcoólatras, drogados, criminosos 'sem motivos', indivíduos à caça de emoções e de distrações. O sentido de insatisfação explica os movimentos de protesto contra a realidade da sociedade, as declarações e os sermões vazios dos revoltados que não se insurgem contra determinado aspecto da organização social, mas contra a própria organização no que ela tem de racionalidade calculista, opondo à má realidade da desumanização e da coisificação o sonho formal de uma existência no puro arbítrio [...]. A insuficiência e o absurdo de tais reações são evidentes, mas a sua sinceridade e a importância do que ela exprime de maneira inadequada não podem ser postos em dúvida" (WEIL, 1996b, p. 94-95). 
a ciência moderna tem no tédio um dos seus principais produtos. É a perda do gosto da vida que gera a "violência 'desinteressada", tornando-nos "insetos nocivos" (WEIL, 1998, p. 202); o tédio, "produzido pela insatisfação de um interesse satisfeito", é fruto da desnaturalização do tempo livre em esvaziamento dedicado à diversão viciosa, que faz da violência gratuita "o único passatempo verdadeiro" (WEIL, 2003a, p. 303). ${ }^{18}$

"O problema do tempo livre" é, portanto, a forma pela qual o indivíduo se torna "problema para a sociedade". A ciência moderna possibilitou largamente o acesso a este antigo privilégio dos senhores, libertando as massas das correntes do trabalho; mas esse tempo, sem educação, pode conduzir a outra condição servil. Com efeito, o mundo moderno condena a escravidão como instituição jurídica e impõe a sua ab-rogação, porém, nele, o escravo ainda existe como o indivíduo "incapaz de descobrir um sentido para a sua existência", e, portanto, incapaz de distinguir entre "quem o subjuga" e "quem o educa para a liberdade" (WEIL, 1996b, p. 247). A “escravidão moderna” existe com a força quase irresistível do resultado do acesso ao tempo livre, de um lado, e da carência de sentido, do outro.

O tempo livre, enquanto condição de possibilidade do otium de massa, se torna o álibi para a violência gratuita e a reflexão sobre o seu papel para a compreensão da nossa época exige um novo retorno ao perfil moderno das ciências. Seja a partir do desenvolvimento técnico que ela permitiu, seja pela imposição do seu como único modelo epistemológico válido, a ciência penetrou todas as esferas da vida

\footnotetext{
${ }^{18}$ Em uma reflexão que se diferencia tanto pelo interesse quanto pelo contexto, as palavras de Charles Taylor parecem ecoar ideia semelhante acerca da potência da violência gratuita quando afirma que "nossas paixões 'inferiores' estão geralmente circundadas por uma aura muito poderosa. $\mathrm{O}$ impulso à violência, por exemplo, está com frequência investido de uma sensação de momento de grandeza. (...) A violência pode ser excitante, pode parecer tirarnos da banalidade de reles existência e nos conduzir a um plano mais elevado, mais enaltecido. (...) Em separado, ou entrelaçados, eles [violência e desejo sexual] podem nos dar uma sensação de alívio do dia a dia, da monotonia do mundo cotidiano" (TAYLOR, 2009, p. 168).
} 
humana; o problema é que ela nos deixou vazios, pois "não possui nenhum meio de nos dizer o que devemos fazer" (WEIL, 1991, p. 288). "A ciência (...) fez de nossa civilização o que ela é, incessantemente modelou e remodelou nossa civilização, dominou nosso mundo" (WEIL, 1991, p. 268); e o fez por meio da riqueza, do poder e do conforto que proporcionou, mas, vale repetir, não acrescentou nenhuma consideração de valor.

Mais uma vez, é este contexto que coloca o problema do papel de uma educação humanística enquanto revela as contradições presentes numa sociedade que assiste a coexistência de uma crescente opulência com o patente aumento dos fenômenos de violência. No que concerne ao tema perseguido aqui, a análise de Eric Weil sobre o tédio oferece os elementos de um quadro referencial social que emoldura a compreensão do nosso tempo numa reflexão que faz da violência $o$ problema da filosofia e traz, na mais fiel inspiração na filosofia clássica, a educação como via de superação de algumas das nossas muitas contradições.

\section{3. "A educação enquanto problema do nosso tempo"}

Se por um lado, a Filosofia política indica claramente o caráter imprescindível da instrução ${ }^{19}$, por outro lado, no que concerne à educação, se limita a dizer que essa se volta à razão, à liberdade, à moralidade. É o que fica claro, por exemplo, no parágrafo em que apresenta o fim da educação como "dar ao indivíduo uma atitude correta nas suas relações com os outros membros da comunidade" (WEIL, 1996b, p. 49), assim como naquele em que a tarefa do filósofoeducador é definida como "discernir a razão no mundo, quer dizer,

\footnotetext{
19 "É certo que a instrução enquanto tal possui um grande valor educativo. É o modo mais fácil e direto de o indivíduo aprender quão pouco suas opiniões, seus desejos e suas preferências pesam quando se trata do que é e do que é verdadeiro: uma data histórica é o que é, a solução de uma equação é correta ou não, uma tradução é correta e elegante ou não o é" (WEIL, 1996b, p. 48-49).
} 
desvelar as estruturas do mundo em vista da realização da liberdade razoável" (WEIL, 1996b, p. 57). São os artigos sobre as humanidades que preenchem essa lacuna, apontando o cerne do processo educativo das ciências humanas, enquanto determinam a relação entre cultura e moral. Nestes mesmos escritos, a instrução técnica é compreendida no papel, ao mesmo tempo indispensável e subordinado, de auxiliar da educação propriamente dita. O interesse de Weil é mostrar que a instrução não substitui a educação e que, por isso, as disciplinas humanísticas não são mero anacronismo nem um conhecimento substancialmente inútil, mas, ao contrário, são a condição de possibilidade da consciência do que somos e do que queremos. As disciplinas humanísticas, filhas da cultura pré-tecnológica, se tornam, no nosso tempo, necessidade da cultura que já conhece muito bem os efeitos da tecnologia.

Os termos da questão estão postos tanto na análise do caráter não reflexivo da cultura científica moderna, quanto naquele essencialmente teórico da filosofia da ciência. De um lado, tem-se o conceito "da nossa forma particular de ciência” (WEIL, 1991, p. 268), subjacente ao debate sobre a divisão entre as ciências da natureza e as ciências do espírito; de outro, as exigências formais que apenas um tipo de filosofia pode expressar. Resta, no entanto, a pergunta pelo sentido que é, para a cultura científica mais rígida, uma questão "cientificamente inexplorável" e um problema infundado, porquanto não pode ser formulado logicamente, afinal, "sobre o que não se pode falar, se deve calar” (WITTGENSTEIN, 1995, p. 85). O nosso contexto é evidentemente aquele formado pela vitória da cultura científica. Porém, não se trata apenas do produto da ciência e da técnica; para essa vitória contribuiu igualmente a pobreza em que caiu a cultura humanística. De fato, de muitas formas a própria filosofia se mostrou incapaz de perceber toda a amplidão da questão fundamental do sentido. Assim, enquanto o sucesso da ciência decreta o fim do que as disciplinas 
humanísticas significaram no passado, essas se deixaram assimilar pelo novo cenário como erudição inútil para a sociedade moderna.

Se a ciência da natureza se tornou um fator de profunda "ruptura na nossa civilização" (WEIL, 1991, p. 290), isso se deu também pela substituição da consciência do pensador humanista pela "inteligência idealmente neutra" do cientista, pretensamente indiferente às questões de valor. Portanto, o problema é ainda aquele de Max Weber: "ela [a ciência] não tem sentido, pois não possibilita responder à indagação que realmente nos importa - 'Que devemos fazer? Como devemos viver?"' (WEBER, 2011, p. 42). E diante da questão de uma saída do aparente vínculo cego formado pela cultura científica, Weil desaprova teorias de pura e simples rejeição. Mesmo se pouco conhecida, a sua crítica figura entre as elaborações mais refinadas do pensamento contemporâneo $^{20}$, pois, para Weil, numa perspectiva capaz de unir vida e saber, a possibilidade de viver como homens educados pelas disciplinas humanísticas e, ao mesmo tempo, trabalhar como técnicos sem lacerar a consciência. Isto exige que também as disciplinas humanísticas reconsiderem a si mesmas, ou seja, que se abram às contribuições do conhecimento científico e técnico, e que se deixem informar por uma filosofia que esclareça a questão do sentido e dos valores, inclusive do valor da ciência.

Duas considerações se impõem. Em primeiro lugar, importa recordar que "nascemos num mundo, não numa multiplicidade de fatos e de valores sem conexão entre eles", isto é, o homem não vive em

\footnotetext{
${ }^{20}$ Trata-se, em última instância, da "educação como problema para o nosso tempo", isto é, "o problema de dar de novo um valor humano à cultura científica moderna, ou seja, de fazê-la viver no horizonte humano, assim como a cultura científica pré-moderna sempre viveu. A tarefa de tornar novamente sensata a ciência objetiva que é, em si, inevitavelmente insensata, enquanto mero conhecimento de fatos" e continua, "tarefa possível apenas se se enxerga no mundo atual 'a queda' e não a inelutável pedra sacrifical do nosso intelecto, como concluía Weber, contentando-se com a probidade do científico, nem com o totem do nosso pretenso desespero, como querem os mestres e epígonos das filosofias da existência". A resposta propriamente weiliana, e aí se mostra a "coragem da razão" de inspiração kantiana, ver em tudo isso "a ocasião oferecida às disciplinas humanísticas de endereçar [o nosso intelecto] no rumo acertado" (TABONI, 1992, p. 37-38).
} 
meio a correntes de causas e efeitos e, como ser dotado de linguagem e de sentimentos, não pode ser tomado como mero objeto da psicologia, da fisiologia, da economia política ou das ciências sociais. Em segundo lugar, "nós não escolhemos os nossos valores antes de começar a viver. O mundo é sempre compreendido antes de se tornar objeto da nossa indagação; e pode se tornar objeto de uma orientação anterior. A compreensão do mundo precede a ciência" (WEIL, 1991, p. 287-288). Subjaz à postura de Weil a busca de outro critério para a cientificidade. Inegavelmente, o sentido das ciências reside na explicação que dão de um dado particular, porém, um dado já antropologicamente compreendido pelas disciplinas humanísticas numa totalidade estruturada. $^{21}$ Em outras palavras, as humanidades são condição de possibilidade para a compreensão das condições do nosso tempo.

Weil, em "Education as a problem for our time", busca o caráter problemático da educação, partindo da constatação de um fenômeno:

Os problemas contemporâneos da educação parecem ser, é o mínimo que se pode dizer, difíceis de resistir. Toda pessoa séria reflete um muito sobre eles, quer dizer, de um modo geral gasta-se muito tempo com as questões acerca da educação superior, secundária ou elementar, da educação de crianças, adolescentes e adultos, de nações bárbaras e civilizadas, dos cidadãos de todos os tipos de Estado, dos membros de assembleias legislativas, administradores, dos quadros sindicais etc. (WEIL, 2003a, p. 297).

Se de um lado, Weil explora a consciência do problema educacional como um todo, de outro, o filósofo registra sua própria posição diante do contexto, afinal,

\footnotetext{
21 “A ciência, que não comporta nenhuma consideração de valor, é 'um empreendimento humano', 'ela só é possível num mundo estruturado e sensato', no mundo real pleno de significação para o [homem] que age nele, para aquele que escolhe 'encontrar nele um sentido'. Assim, a própria ciência, que não enuncia julgamentos de valor nem tem interesses, (...) é retomada, mas não transformada; ou melhor, ela é realocada, salvaguardando os caracteres que a epistemologia contemporânea reconhece nela" (SICHIROLLO, 1985, p. 390).
} 
"para abordar essas questões, existem associações privadas, ministérios da Educação, reuniões, simpósios; existe a Unesco; existem defensores de valores nacionais sagrados. O que há ainda para dizer acerca de um tema sobre o qual, se a probabilidade é válida nesses domínios, tudo já deve ter sido dito e repetido tantas vezes?" (WEIL, 2003a, p. 297).

A primeira questão é aquela acerca da justificativa para se retomar o tema da educação. É justamente essa pergunta que permite colocar com uma maior precisão o objetivo da reflexão weiliana. Para o autor, com efeito, o que se tem é o quadro que desfruta de uma "profusão de propostas de receitas", enquanto nem sempre sabemos "quais os problemas que essas respostas deveriam resolver" (WEIL, 2003a, p. 298). Ou seja, o filósofo se coloca nessa discussão com o objetivo específico de ajudar a recordar, afinal, "do que trata a educação" (WEIL, 2003a, p. 298).

Para tanto, Eric Weil busca outra perspectiva da questão ancorando-se na análise da experiência dos séculos XVIII e XIX, quando, sobretudo neste segundo, a pergunta pelo que consistia a educação tinha uma resposta clara: "a educação é a instrução" (WEIL, 2003a, p. 198). ${ }^{22}$ Subjazem à sua ótica duas ideias que devemos considerar e manter presentes em nossa própria análise do problema da educação. Em primeiro lugar, a ambiguidade da situação do mundo atual em que, de um lado, uma grande parte da humanidade ainda vislumbra a instrução e o desenvolvimento técnico como um ideal distante e, de outro lado, o fato de que nos países ocidentais, praticamente toda a população já foi instruída. No entanto, temos que admitir que a marcha do mundo não se tornou mais harmoniosa por causa disso e que as pessoas também não se tornaram mais pacíficas

\footnotetext{
22 "Entendida bem, a instrução nem sempre é suficiente. Em países como a Inglaterra, a França e a Alemanha, havia um outro ideal transcendendo a instrução pura: o gentleman, o homem do mundo, der edle Charakter (ou ainda, e a alternativa é significativa, der grosse Mann) não poderiam ser produzidos por meio da instrução; e quando a instrução fosse pedida (nem sempre foi o caso), ela era apenas uma condição prévia principal” (WEIL, 2003a, p. 298).
} 
depois de instruídas. Em segundo lugar, e isso é essencialmente importante, devemos considerar também que os homens que durante os séculos XVIII e XIX insistiram sobre a necessidades da educação popular, em geral, não acreditavam que a instrução fosse um fim em si mesma.

Se a resposta do século XIX rompe com a educação humanística, se nós mesmos já não nos satisfazemos com ela, nos convencemos de que a pergunta pela educação, isto é, a assunção do seu caráter problemático, subjazem questões que envolvem, ao mesmo tempo, uma nova visão de mundo assim como uma nova visão de homem. Trata-se, em última instância, do real breakthrough (WEIL, 2003a, p. 193-224) da saída do período em que "todas as coisas estavam bem ordenadas, cada uma estava em seu lugar natural, e todas as instituições eram sensatas e satisfatórias" (WEIL, 2003a, p. 299). Portanto, o problema da educação testifica a passagem à moldura da sociedade moderna, segundo a qual a instrução é a condição necessária, embora insuficiente, do "aparecimento do homem novo", ou seja, do homem

capaz e desejoso de desempenhar seu papel na sociedade moderna, pronto e apto para julgar todos os problemas concernentes à vida da comunidade à qual pertence, satisfeito com a própria posição porque é consciente da dignidade inerente e da necessidade social de seu trabalho, convicto do caráter razoável da ordem existente, mas determinado a melhorá-la tanto quanto a melhorar a posição que ele mesmo ocupa dentro dela (WEIL, 2003a, p. 299).

Trata-se, então, do imaginário no qual "a instrução é o meio, o progresso, o fim” (WEIL, 2003a, p. 299). Em primeiro lugar, é nesse novo quadro referencial social que se exige cada vez mais o reconhecimento dos valores subjacentes ao progresso, pois esses mesmos valores parecem ser o destino de uma sociedade "colonizada" por uma "razão sistêmica", cujo "sagrado", em seu caráter essencialmente abstrato, é insuficiente para orientar a ação individual e coletiva. Como já dissemos, a educação se torna de novo um problema, 
porque o homem e o mundo são compreendidos a partir de um contexto incapaz de fundar uma vida sensata, isto é, uma vida na qual o homem possa viver segundo princípios morais concretos e universalizáveis. Em segundo lugar, nessa moldura, a educação entendida como problema da inserção do indivíduo na comunidade, como a superação de si mesmo em vista da sua integração num corpo normativo que lhe permita ultrapassar a contingência de sua individualidade. Por último, é também o cenário no qual a tarefa do filósofo-educador pode ser analisada de forma mais precisa. É o filósofo que deve compreender o problema da educação a partir do risco da sua redução à instrução, sem esquecer, porém, o papel educativo próprio da instrução, enquanto,

[...] ela é o meio mais fácil, mais direto, para que o indivíduo aprenda quão pouco valem suas paixões, seus desejos, suas preferências, quando se trata do que é e do que é verdadeiro: uma data histórica é o que é, a solução de uma equação é correta ou não é, uma tradução é correta ou elegante ou não é (WEIL, 1996b, p. 48-49).

De fato, se por um lado os conhecimentos técnicos são imprescindíveis para a participação do mecanismo social, por outro, não se pode confundir sua imprescindibilidade com a educação. Logo, o filósofo-educador não nega o valor da instrução, mas a considera a partir do seu aspecto verdadeiramente fundamental, aquele de submeter o indivíduo à objetividade e à universalidade da racionalidade. Trata-se, portanto, de um passo prévio indispensável à educação, porquanto habilita o indivíduo não apenas ao discernimento entre o eficiente e o ineficaz, isto é, a avaliar a utilidade de seus empreendimentos, mas, acima de tudo, o introduz no contexto social. ${ }^{23}$

Justamente aqui vemos o choque entre o ideal e o real ao redor da instrução enquanto se assenta sobre o fim último do progresso. Esse

\footnotetext{
${ }^{23}[\ldots]$ uma opinião tão injusta quanto sem fundamento consiste em supor que os homens são aptos só para serem adestrados a determinadas funções [...] mas não para desempenhar ora uma função ora outra, sem perder a sua identidade (WEIL, 1996b, p. 49).
} 
choque se põe na pergunta sobre os meios disponíveis para possibilitar o acesso às condições de bem-estar social. Eric Weil não apenas reconhece o problema, mas o mostra em sua lógica própria, isto é, na imagem de uma relação dialética cuja síntese parece impossível: "as pessoas são pobres porque lhes falta a instrução sobre os meios e os recursos de uma sociedade moderna, industrial e racional e isto lhes falta porque são pobres" (WEIL, 1991, p. 300). Para uma leitura apressada, a educação pode ser tomada, então, como a solução definitiva pela quebra do círculo que comprime a pobreza e pela inclusão progressiva das pessoas das regiões atrasadas no domínio do progresso social e político das sociedades desenvolvidas. Logicamente, pessoas e comunidades que não dispõem das melhores condições materiais também desejam desfrutar dos produtos da tecnologia, o que exige delas a disposição para tomar parte num mecanismo que se movimenta em função de um progresso sem fim, o que lhes impõe, como contrapartida, a exigência de um grau de instrução sempre mais sofisticado. Finda-se por se colocar a questão da formação do técnico e não a do sentido do homem, donde decorrem as mudanças das suas concepções acerca dos valores fundamentais da vida humana.

Eric Weil assume uma perspectiva positiva da educação, entendida sempre como meio de transformação social, prescindindo de um discurso que a análise sob o prisma de instrumento de manutenção das desigualdades, tema comum à sociologia da educação das últimas décadas. Mantém-se também nos limites impostos pelo "esforço do conceito", isto é, do ponto de vista próprio da filosofia que, como atividade "eminentemente científica", reconhece que "suas regras, se as tiver, não são específicas, mas revelam a lógica mais comum e mais geral (não da lógica formal generalizada, mas daquela comum a todos), a lógica do diálogo" (WEIL, 1970, p. 355), o que não apenas sugere o respeito às "regras do diálogo", mas que se compreenda o próprio saber como "ciência do diálogo" (WEIL, 1996a, p. 23-24). 
No que concerne ao problema da educação, o passo decisivo pode ser feito na proposta de uma compreensão alternativa da noção de cultura e do homem educado.

\section{A coragem da razão: o filósofo-educador e o homem culto}

O problema pode ser tomado no texto "La culture", no qual podemos sublinhar algumas ideias essenciais da noção weiliana da educação. O escrito inicia pela definição do "homem culto", noçãochave da nossa interpretação, pois o entendemos, essencialmente, como "homem educado". ${ }^{24} \mathrm{O}$ ponto de partida é o uso do termo na linguagem comum, aplicado indistintamente em expressões como a "boa cultura geral" e outras como "cultura técnica", "cultura jurídica", "cultura comercial", "cultura popular", do que segue saber se "devemos nos perguntar se a cultura não acabou se tornando uma dessas senhoras cuja reputação torna-se duvidosa por ser difundida demais" (WEIL, 2003b, p. 3), o que faz pensar o esvaziamento do termo pelo seu uso abusivo.

A primeira tarefa é definir qual o significado do termo. O procedimento de Weil é peculiar, pois pensa a cultura a partir do "retrato" do homem culto, ou seja, "a cultura, digamos, é o que o homem culto faz, e o homem culto, o que é? Pois bem, o humanismo, do qual tiramos esse ideal, foi dito e repetido à exaustão: é o homem eloquente" (WEIL, 2003b, p. 3), "o homem de bem e que sabe falar" (WEIL, 2003b, p. 4). Se, numa primeira definição, a cultura, ou, mais precisamente, o homem culto, se assemelha à imagem tradicional do sofista, continua a valer a crítica platônica que Weil retoma: "saber falar é necessário, mas isso não é tudo. Importa saber o que se fala"

\footnotetext{
${ }^{24}$ Há na obra de Weil duas formas distintas de utilizar os termos relativos à cultura, no texto que tomamos aqui, o autor apresenta a figura do homme cultivé, enquanto no artigo "La vertu du dialogue", encontramos o homme de culture (WEIL, 2003a, p. 294). Não é o caso de apresentar as diferenças entre as duas figuras, mas apenas de sublinhar o fato de que ambas coincidem essencialmente na sua oposição à violência, o que, segundo a nossa interpretação, permite tomá-lo também como o homem educado.
} 
(WEIL, 2003b, p. 4). Para o nosso escopo, a retomada da crítica de Platão alarga as concepções de modo "que nosso homem culto seja um homem de bem, não apenas um homem que, como se diz, 'saiba conversar"” (WEIL, 2003b, p. 4). Logo, não é o caso de mera erudição à qual a atitude do sofista é tão afeita, mas de uma perspectiva ampla que relaciona a noção de cultura a uma determinada concepção compartilhada de bem.

Os contornos propostos por Weil nos levam à colocação do problema em termos específicos, pois se a cultura deve ser compreendida a partir do homem culto é preciso também reconhecer que a própria noção de homem culto pode ser abordada apenas em suas diferentes formas históricas. "O orator de Cícero e de Catilina, o courtisan de Castilhone, o homem honesto do século XVII, mesmo o Kalos lagathos de Platão, o anèr agathos de Aristóteles figuram entre os ancestrais do homem culto" (WEIL, 2003b, p. 4). Dito de outra forma, o retrato do homem culto supera a figura daquele que se define simplesmente pelo falar ou pelo falar bem. Se, por um lado, não se duvida da sua capacidade de fala, de outro, a noção do "homem de bem", ou seja, do homem de "boa cultura" passa a ser o "verdadeiro homem honesto", "aquele que não se orgulha de nada" (WEIL, 2003b, p. 5). No entanto, essa definição nos coloca diante de outra questão, pois é perfeitamente possível pensar num homem bom, de gosto aceitável e mesmo de conhecimento razoável, sem que o mesmo seja, necessariamente, considerado um homem culto. Trata-se concretamente do problema levantado a partir da relação entre o vir bonus e o vir bonus dicendi peritus, quer dizer, entre o "homem de bem" e o "homem culto".

A tarefa decorrente dessa primeira conclusão lida justamente com a articulação das consequências da relação entre o homem culto e o homem bom. Afinal, se nos é permito afirmar que o homem bom não precisa ser culto, mas que este último necessariamente deve ser bom, a pergunta é: em que consiste a bondade do homem culto? Segundo a 
reflexão de Eric Weil, "o homem culto é um homem bom, porque ele é razoável, porque ele sabe como julgar e distinguir a verdade do falso, o valor autêntico da falsificação" (WEIL, 2003b, p. 6). Isso não significa, porém, que todas as questões foram superadas, pois, e a realidade não nos deixar negar, "os céticos dirão, qual é o valor autêntico?" (WEIL, 2003 b, p. 6). De novo, o procedimento de Weil surpreende, porque não se parte simplesmente de uma noção abstrata de bem para alcançar a noção de valor, antes, o filósofo o compreende a partir das formas históricas da sua realização: "a resposta é menos difícil para descobrir do que poderia parecer depois de tanta discussão: [o valor autêntico] é o contentamento" (WEIL, 2003b, p. 6). Logo, "o homem culto é essencialmente o homem contente" (WEIL, 2003b, p. 6). O problema ganha contornos mais precisamente weilianos, porquanto o homem culto é apresentado como "essencialmente contente", do mesmo modo com que o indivíduo moderno é entendido como "essencialmente insatisfeito". A distinção fundamental entre eles se encontra no fato de o primeiro procurar o seu contentamento enquanto o segundo busca a própria satisfação. A distinção, portanto, está na meta à qual os homens se propõem, ou seja, o que os distingue, fundamentalmente, está na perspectiva a partir da qual cada um olha o mundo, segundo à medida do "cultivo" do próprio olhar. ${ }^{25}$

No entanto, se o homem culto se mostra sob diversas figuras, pois, a cada novo período histórico, uma forma de compreensão da cultura se põe sempre como o pano de fundo a partir do qual se pode avaliar as práticas, as instituições e os modelos de conhecimento. Com outras palavras, existe a possibilidade de julgamento das coisas, das ações, das

\footnotetext{
${ }^{25}$ Com efeito, "ser culto, é reconhecer, é saber reconhecer os valores do mundo (e é nesse ponto que se encontra a concepção latina de homem civilizado e a ideia germânica da Kultur: a Kultur particular é de um país, de uma época, de um grupo, é a totalidade orgânica dos valores de um mundo histórico). Ser culto, é buscar e encontrar o contentamento, a paz, a resposta no desfrute das belezas e das verdades, das tradições e das tendências do espírito, dos sentimentos e dos pensamentos. Aquele que é privado dessa possibilidade de gozo e de contentamento, é o pedante, o banausos, o bárbaro" (no sentido moderno da palavra) (WEIL, 2003b, p. 7).
} 
experiências e dos seus resultados, por que o homem está sempre inserido num universo de pré-compreensão cultural. Logo, se há coisas boas é a cultura que as torna possíveis, e se se deseja maximizar o que se considera valioso, deve-se preservar e fortalecer a cultura que o sustenta. Trata-se, portanto, de se repensar não apenas a cultura, mas essencialmente também a filosofia e a educação confrontadas com as formas presentes que as ameaçam. A cifra da tarefa do filósofoeducador é, portanto, a compreensão da natureza da sua tarefa diante da violência, o que, no tempo atual, obriga a considerá-la nas suas duas formas ideais, usando a linguagem weberiana.

No primeiro caso, trata-se da linguagem da "violência pura" que Weil encontra traduzida historicamente nos movimentos totalitários e pela sua recusa do discurso absolutamente coerente; é a possibilidade de refutar o que os "homens de cultura" (WEIL, 2003a, p. 287) representam. Weil ilustra com uma historieta: "Um chefe da SS declarou um dia numa reunião pública: 'Quando eu ouço a palavra cultura, saco meu revólver" (WEIL, 2003b, p. 8). ${ }^{26} \mathrm{Se}$, de um lado, os "homens de cultura" (WEIL, 2003a, p. 287) podem ver nessa recusa a violência na sua pureza, de outro, abre-se o espaço à pergunta: "por que o homem, [um chefe da SS] detestaria a este ponto a cultura e o homem culto?" (WEIL, 2003b, p. 8). Não se trata apenas de uma relação de "negação determinada" na qual os termos são postos num processo dialético em que as negações são superadas. ${ }^{27} \mathrm{O}$ corpus weiliano

\footnotetext{
${ }^{26} \mathrm{O}$ que nos remete imediatamente ao que o filósofo afirma na Lógica da filosofia: "O pensamento deve estar bem avançado para que alguém possa declarar que saca seu revólver assim que ouve a palavra "civilização" (WEIL, 1996a, p. 60). Logo, a arma apontada é um Não à altura do pensamento negado, no caso da filosofia weiliana, é uma recusa absoluta ao discurso, pois se dá, logicamente, como a recusa ao discurso absoluto. É essa a novidade que se impôs nas formas da violência do século passado, e que a filosofia deve compreender. Em outros termos, só na contemporaneidade, portanto, a filosofia pôde pensar "a violência em toda a sua pureza" (WEIL, 1996a, p. 60).

${ }^{27}$ Em termos definitivos, "o homem culto se distingue de todos os outros homens por um traço, um único traço, mas o suficiente para torná-lo um monstro e um objeto de desgosto por todos os outros: ele reprova a violência. Ele não acredita, ele não quer acreditar que
} 
retoma a oposição à violência como caráter constitutivo da vida do "homem razoável" (WEIL, 1996a, p. 4), quer como "homem de cultura", "homem de diálogo" (WEIL, 200a3, p. 292) ou "homem culto", quer como "filósofo". Podemos, finalmente, projetar a contradição no nível da história, pois o homem culto se torna um ideal a ser realizado; "o que nos importa é justamente a oposição aberta entre a cultura que faz o homem culto e - e o que? A violência? Podemos nos servir desse termo" (WEIL, 2003b, p. 9).

No segundo, aparece outra figura igualmente moderna da violência, aquela do homem que se compreende exclusivamente a partir dela, ou seja, que vê a si mesmo e a própria realidade a partir da violência sofrida. De um modo geral, mas não o único, seria o discurso das "filosofias da existência" 28 , discurso no qual o sentido da vida e do mundo está essencialmente marcado pela própria finitude humana (WEIL, 2003b, p. 9-10).

Portanto, o homem culto se vê confrontado com essas duas figuras modernas da violência. De um lado, está às voltas com aqueles que negam qualquer apelo à razão, os "violentos puros" (WEIL, 2003a, p. 10), de outro, deve lidar também com o discurso de quem vê na violência padecida a única substância da realidade, negando valores, sentidos e ideais. Eric Weil põe diante das diferentes formas de violência "o jardim do homem culto"; nele, o homem educado não se afasta do mundo, mas compreende a si mesmo a partir da sua recusa à violência. Ele reconhece que tudo o que é valioso o é apenas em sua

haja coisas, opiniões, decisões pelas quais se valha a pena morrer ou matar" (WEIL, 2003b, p. 8).

${ }^{28}$ Sobre as filosofias da existência, podemos remeter à forma mesma com que Weil resume seu discurso: "Eis o que dirá esse homem: 'Eu sofro, eu desejo, eu vou morrer. Eu luto e eu me debato. Serão meu sofrimento e minha luta menos imediatamente presentes a mim porque o saber absoluto (e eu mesmo posso, se quiser, por meio desse saber) compreender e reconciliar as contradições entre mim e a violência da luta e da morte, porque ele pode superar meu desespero e rumar para o sentido absoluto no qual eu desapareço? Será a violência menos violência para mim por ser violência compreendida, compreendida por um saber que me destrói, eu que sofro e luto e trabalho e vou morrer?"' (WEIL, 1996a, p. 56). Sobre a crítica de Weil ao existencialismo, pode-se ver também (BERNARDO, 2006). 
cultura, logo, se quiser manter o que considera um bem, deve preservar e fortalecer o pano de fundo sobre o qual as coisas, as instituições e os modelos de conhecimento adquirem e revelam o próprio valor. Logo, para o homem culto, assim como para o filósofo-educador, importa eliminar a violência e não apenas se afastar dela; importa, "reforçar os muros do seu jardim, evitar os violentos, aumentar por uma ação pacífica, pelo discurso esclarecedor e pedagógico, as oportunidades de concórdia" (WEIL, 2003b, p. 10). O que está em jogo é a realização do homem, pois, em última instância, "é entre os verdadeiros homens que a violência é proibida" (WEIL, 1996a, p. 25). Finalmente, se o homem culto é o homem contente, só pela eliminação da violência "ele poderá se livrar de uma vida a partir da qual o contentamento é excluído" (WEIL, 2003b, p. 10).

O jardim não é a única imagem de Weil para o homem culto. Para o autor da Lógica, esse pode ser compreendido ainda como aquele que habita uma torre ebúrnea. Nesta torre, a violência se mostra positivamente na história e exige do filósofo-educador a crítica inclusive da própria cultura em vista da possibilidade da violência ao seu redor e dentro também dos seus próprios ideais culturais. Ele se vê acompanhado pela violência em sua torre de marfim e chega à conclusão de que qualquer vitória sobre ela é sempre precária. ${ }^{29}$

Essa vitória é sempre precária, pois, de outro modo, sequer teria sentido falar de vitória. Logo, devemos perguntar: "a grandeza, a beleza, a graça, as boas maneiras, a honestidade, o desinteresse, tudo isso não é vitória sobre a violência, violência da natureza, violência dos

\footnotetext{
29 "Se ele devesse encontrar violência em seu próprio ideal, se tivesse que admitir que o que ele desfruta não é apenas o produto presente da violência passada, da luta do homem com o homem, da luta do homem com a natureza, mas ainda que, agora, neste momento em que ele desfruta da cultura, em que, como homem culto, desfruta, julga, aprecia tudo o que tem valor, que mesmo neste momento a violência está presente, não como uma força exterior e distante no tempo ou no espaço, mas no fundo do seu desfrute? Que a torre de marfim não só precisa de um fundamento de ouro e de um muro de aço, mas que o homem culto não a habita sozinho e que a violência entrou ali com ele para não mais deixá-lo?" (WEIL, 2003b, p. 10).
} 
homens, violência no próprio homem culto? Que restaria disso tudo se a violência desaparecesse da face da terra?" (WEIL, 2003b, p. 11). Em linguagem weiliana, a cultura, como a filosofia e a educação devem ser compreendidas como a vitória sobre a violência, não a sua exclusão ou a sua negação verbal e artificial. A vitória que se busca se dá no domínio do pensamento, mas não como pensamento abstrato, quer dizer, separado do que lhe dá sentido, mas no terreno do pensamento que sabe do perigo que corre, mas que se quer sempre em perigo, como pensamento agente, "pensamento que é ação, ação que é pensamento, em vista do contentamento" (WEIL, 2003b, p. 12).

É nessa altura que as definitivas questões podem ser colocadas. No fundo de todo procedimento filosófico está um ato livre e corajoso do homem que quer compreender as atitudes e os discursos dos homens. A violência revelou não apenas "o medo do homem filósofo" (WEIL, 1996a, p. 19), mas também a "coragem filosófica" (WEIL, 2003b, p. 12), "ele é corajoso" (WEIL, 1996a, p. 19), sobretudo quando sabe que o que está em jogo é a sua tarefa fundamental, tarefa que constitui sua identidade, pois ele mesmo só se compreende como "homem que busca realizar o homem" (WEIL, 2003a, p. 282). O "homem culto", o "homem da cultura", o homem educado, é, essencialmente, aquele que educa.

\section{Considerações finais}

A reflexão filosófica sobre a educação não se restringe ao campo de uma ciência pedagógica apenas, porquanto, considerando as dimensões da moral e da política envolvidas, não existe ciência que, sozinha, compreenda o terreno, o sentido e a finalidade da educação. Do mesmo modo, deve-se insistir no fato de que a educação no seu sentido mais amplo é o escopo das humanidades e não da instrução técnica. Com efeito, se hoje o conhecimento técnico é mais indispensável do que em qualquer época passada, ainda não pode 
substituir ou suplantar as humanidades. Logo, a justa relação entre a instrução e a educação se dá, nas palavras de Eric Weil, quando "a instrução está a serviço da educação", e acrescenta, "esta não pode nunca ser a serva daquela" (WEIL, 1996b, p. 49).

Para Weil, trata-se de uma "crise moral da educação", que não é problema exclusivo das modernas técnicas pedagógicas (NGUYENDINH, 1996, p.79-86). De fato, o procedimento das novas técnicas de ensino não difere muito, por exemplo, daquelas da ciência social, ou seja, não dispõe de um discurso verdadeiramente relevante acerca da crise moral de um mundo formado pela cultura científica. Só as disciplinas humanísticas podem, então, nos ajudar a compreender esta crise, o que supõe um esforço iluminado por conteúdos morais, afinal, "Emílio não é um homem problemático" (WEIL, 1996b, p. 53), porque é educado e não apenas instruído.

A perspectiva weiliana caminha na direção de um horizonte original. Não ignora nem subvaloriza o problema da adequação das estruturas da instrução às exigências da sociedade moderna. Simplesmente, para evitar uma solução eficientista, antepõe a isto a pergunta pela natureza da educação. Fundamentalmente, Weil, nos seus textos sobre disciplinas humanísticas, não põe outra questão senão o sentido da educação na era da ciência.

Desta feita, o autor se coloca numa posição muito peculiar na filosofia contemporânea por pelo menos três razões.

Em primeiro lugar, pela coragem de resgatar o tema da educação. Weil não é o único a fazê-lo, mas busca assumir a real dimensão do problema no "nosso tempo", sem fazer do tema um anexo à filosofia, mas assumindo-o como condição de possibilidade da compreensão da própria filosofia enquanto desvela a tarefa social do filósofo.

Em segundo lugar, evita qualquer postura unilateral. Em outras palavras, não é o caso de uma declaração de guerra à ciência e à técnica, mas do desejo de compreender o sentido das mesmas no nosso mundo, esforço que extrapola os limites conscientes de ambas, mas 
reside no centro mesmo da educação humanística, porque tem a ver, em última instância, com a questão do sentido em sua completude. A palavra de ordem da filosofia weiliana é, de fato, compreensão, isto é, o esforço de "prender juntas as contradições" (WEIL, 1996a, p. 425), por isso não se pode abrir mão de nada, mas considerar, ao mesmo tempo, quer as questões dos fatos, próprias ao domínio das ciências da natureza, quer aquelas do sentido, que só podem ser pensadas no horizonte da cultura humanística.

Em terceiro lugar, ao assumir a violência como $o$ problema da filosofia, Weil não apenas se coloca numa posição particular na história do pensamento contemporâneo, mas dá ao problema da definição da filosofia e da educação uma nova cifra. Mantendo-se na certeza de que "um pensamento abstrato não é necessariamente um pensamento que se ocupa de objetos abstratos" (WEIL, 1993, p. 101), Weil caminha na direção de uma fidelidade crítica ao credo filosófico na razão. A fidelidade está justamente na escolha da linguagem, ou seja, na opção pela filosofia. A crítica se faz ao renunciar qualquer leitura otimista de uma hegemonia da razão.

Em Weil, por trás de tudo está a pergunta "o que é o homem?" (WEIL, 1996a, p. 10). Já não é possível uma resposta que simplesmente identifique o homem à razão, quer à razão "mecânica" (WEIL, 1993, p. 99), quer à "desrazoável” (WEIL, 1996a, p. 17). O que se busca é de fato uma "razão razoável" (WEIL, 1996a, p. 17) que oriente o homem tanto no campo prático e naquele teórico, do que resulta que "nada de humano se fez, nada de humano jamais se fez sem educação" (WEIL, 1996b, p, 48).

\section{Referências}

ARENDT, H. Crises of the Republic. New York - London: Harvest, 1972. 
ARENDT, H. The crisis in education. In: Between past and future: eight exercises in political thought. New York: Penguin Books, 1983. p. 173-196.

ASSIS, F. Educação e moral: uma análise crítica da filosofia de Eric Weil. CRV: Curitiba, 2016.

BERNARDO, L. M. Moral, Educação e Sentido: uma leitura da Philosophie morale de Eric Weil. Itinerarium, v. 57, p. 3-40, 2011.

BERNARDO, L. M. Reasons of violence. Violence of reason: an interpretation based on Eric Weil's core paradox. In: AURÉLIO, D. P.; PROENÇA, J. (Org.). Terrorism: Politics, Religion, Literature. Cambridge: Cambridge Scholars Publishing, 2011a, p. 35-67.

BERNARDO, L. M. O herói moral na Filosofia Moral de Eric Weil. Argumentos, v. 11, p. 29-48. 2014.

BERNARDO, L. M. Liberdade ou Satisfação: a crítica de Eric Weil ao Existencialismo. In: Actas do Colóquio Internacional Jean Paul Sartre: uma Cultura da Alteridade, Filosofia e Literatura. Lisboa: Faculdade de Ciências Sociais e Humanas da Universidade Nova de Lisboa, 2006, p. 277-290.

CAILLOIS, R. La violence pure est-elle démoniaque ?. In: Actualité d'Eric Weil. Actes du Colloque International, Chantilly, 21-22 mai 1982. Paris: Beauchesne, 1984, p. 213-222.

CANIVEZ, P. Éducation et instruction d'après Eric Weil: implications sociales, politiques et morales de l'action éducative. Archives de Philosophie, v. 48, p. 529-562, 1985.

COSTESKI, E. Atitude, violência e Estado Mundial democrático. Sobre a filosofia de Eric Weil. Fortaleza: Unisinos, 2009a.

LINS JÚNIOR, D. Ação e sentido na Logique de la Philosophie de Eric Weil. Argumentos, v. 11, p. 172-189, 2014.

KIRSCHER, La philosophie d'Eric Weil. Paris: Presses Universitaires de France, 1989. 
KLUBACK, W. Eric Weil. A fresh look at philosophy. New York: University Press of America, 1987.

LABARRIÈRE, P. J. Le discours de l'altérité. Une logique de l'expérience. Paris: PUF, 1983.

NGUYEN-DINH, L. Éducation ou violence selon Eric Weil. In: QUILLIEN, J.; KISCHER, G. (Orgs. Cahiers Eric Weil V. Lille: P. U. L., 1996. p. 79-86.

PERINE, M. Eric Weil e a compreensão do nosso tempo. Ética, política e filosofia. São Paulo: Loyola, 2004.

PERINE, M. Filosofia e violência. Sentido e intenção da filosofia de Eric Weil. São Paulo: Loyola, 1987.

ROBINET, J. F. O tempo do pensamento. São Paulo: Paulus, 2004.

SALDIAS, R. Cultura, Humanidades y Universidade en el pensamiento filosófico de Eric Weil. Argumentos 11 (2014), p. 98-118.

SICHIROLLO, L. Réflexions sur Eric Weil. Kant après Hegel (et Weber). In: L'Héritage de Kant. Mélanges philosophiques offerts au P. Marcel Régnier. Paris: Beauchesne, 1982, p. 385-395.

SOARES, M. C. O filósofo e o político segundo Eric Weil. São Paulo: Loyola, 1998.

SOETARD, M. Eric Weil: Philosophie et éducation. In: Actualité d'Eric Weil. Actes du Colloque International, Chantilly, 21-22 mai 1982. Paris: Beauchesne, 1984, p. 289-298.

STRUMMIELLO, G. Filosofia e metafilosofia in Eric Weil. In: WEIL, E. Violenza e libertà. Scritti di morale e politica. Milano: Mimesis, 2006, p. 101-119.

STRUMMIELLO, G. Il logos violato. La violenza nella filosofia. Bari: Dedalo, 2001.

TABONI, P. F. Introduzione. In: WEIL, E. Educazione, istruzione e disciplina oggi. Milano: Guerini e Associati, 1992, p. 9-45.

TAYLOR, C. Uma era secular. São Leopoldo: Unisinos, 2010. 
WEBER, M. Ciência e política: duas vocações. São Paulo: Cultrix, 2011.

WEIL, E. La philosophie est-elle scientifique? Archives de philosophie, v. 33, p. 353-370, 1970.

WEIL, E. Essais et confèrénces 1. Paris: Vrin, 1991.

WEIL, E. Essais sur la philosophie, la démocratie et l'éducation. Lille: Presses Universitaires de Lille, 1993.

WEIL, E. L'Avenir de la philosophie. In: QUILLIEN, J. (Org.). Cahiers Eric Weil I. Huit etudes sur Eric Weil. Lille: PUL, 1987, p. 921.

WEIL, E. Limites de la démocratie. Evidences, v. 13, p. 35-39, 1950.

WEIL, E. Logique de la philosophie. Paris: Vrin, 1996a.

WEIL, E. Philosophie et réalité I. Paris: Beauchesne, 2003a.

WEIL, E. Philosophie et réalité II. Paris: Beauchesne, 2003b.

WEIL, E. Philosophie morale. Paris: Vrin, 1998.

WEIL, E. Philosophie politique. Paris: Vrin, $1996 \mathrm{~b}$.

WEIL, E. Response to the Unesco Questionnary on ideological conflits concerning democracy. In: McKEON, R. (Ed.). Democracy in a world of tensions: a symposium prepared by Unesco. Chicago: University Chicago Press, 1951. p. 425-442.

WITTIGENSTEIN, L. Tractatus logico-philosophicus. In: Werkausgabe Band 1. Frankfurt: Suhrkamp, 1995.

Data de registro: 08/01/2018

Data de aceite: $26 / 09 / 2018$ 